\title{
Seasonal changes in the nematode fauna in pine trees killed by the pinewood nematode, Bursaphelenchus xylophilus
}

\author{
Rina Sriwati, Shuhei Takemoto and K azuyoshi Futai ${ }^{1}$
}

\begin{abstract}
The seasonal changes in the number of free-living nematodes and the pinew ood nematode (PWN), Bursaphelenchus xylophilus, in 15-year-old Japanese black pine (Pinus thunbergii) trees killed by the PWN were determined. Fifteen species of nematodes were isolated, i.e. one species, each of M ononchida and Plectidae, two species, each of Monhisterida, Rhabditida and Tylenchida, three species of Bursaphelenchus including the PW N, and four species of Diplogasterida. The PW N and one species of Diplogasterida were the most prevalent nematodes isolated. The numbers of PWNs decreased from A ugust to December, 2004, but then increased in February, 2005, then decreased again until June, 2005. During the experimental period the population changes of the Diplogasterida nematode mimicked those of the PW N, however, correlations between the numbers of the two nematodes varied considerably both among trees and seasons. Both the PW N and the Diplogasterida nematode were more abundant around the pupal chambers of the vector beetle, M onochamus alternatus, than elsewhere in the tree wood. Jpn. J. Nematol. 36 (2), 87-100 (2006).
\end{abstract}

Key words: pine wilt disease, nematode community, population dynamics.

\section{INT RODUCTION}

Pine wilt disease, caused by the pinewood nematode (PWN), Bursaphelenchus xylophilus Steiner $\&$ Buhrer, is a major threat to pine forests in Japan. In Japan and elsewhere its spread is so rapid and the resulting damage is so serious that to date extensive areas of pine forests have been destroyed (Mamiya, 1988). The PW N occurs over a wide area in Japan and in other A sian countries (Mamiya, 1988, 2004; $Y$ ang, 2004). This disease is supposed to have

\footnotetext{
Laboratory of Environmental Mycoscience, Graduate School of A griculture, Kyoto University, Kitashirakawaoiwake-cho, Sakyo-ku, K yoto 606-8502, Japan.

Tel. +81-75-753-6060; Fax +81-75-753-6429.

${ }^{1}$ Corresponding author, e-mail: futai@ kais.kyoto-u.ac.jp
}

originated in North A merica (de Guiran and Bruguir, 1989) and recently it has been found in Portugal (M ota et al., 1999).

A cerambycid beetle, M onochamus alternatus Hope, vectors the PW N (Mamiya and Enda, 1972; Morimoto and Iwasaki, 1972). Numerous PW N s aggregate around $M$. alternatus pupal chambers (PC) in wilt-killed pine trees and the emerging beetles carry many nematodes and they inoculate them into healthy trees during maturation feeding. The profuse growth of blue stain fungi on the walls of $M$. alternatus $P C$ serve as a food source for PW Ns which proliferate and aggregate in the chambers. Thus, the beetles that emerged from the chambers acquire many PW Ns both externally and internally (Maehara et al., 2005). 
Blue-stain fungi only occur in the sapwood and are commonly associated with wood-inhabiting insects. When insect feed on the trees, sapwood-decaying fungi and other microorganisms rapidly invading the wood. Competition is intense among organisms inhabiting dead trees, including PW Ns, and environmental factors, especially temperature, moisture, substrate, and other biotic or abiotic factors, or both, greatly affect their successions (Shigo, 1967). Organisms, including the PWN and the other nematode cohabitants, must continuously adapt to these changing conditions if they are to survive.

A $n$ earlier study clarified the seasonal changes in the numbers of PW Ns and other freeliving nematodes, and their interrelationships (F ukushige and Futai, 1987). However, that study did not show the species composition of the 'free-living nematodes' and so the interaction between the PW $\mathrm{N}$ and each species of free-living nematode remained unclear.

In the present study, we investigated the nematode fauna in the stems of pine trees after infection by the PW N to: (i) clarify their seasonal changes and the interrelations between the PW N and the other species comprising the nematode fauna, and (ii) examine the effect of PC of $M$. alternatus on the nematode populations.

\section{MATERIALS AND METHODS}

PW N inoculation:

A virulent isolate (S10) of the PW N, was cultured on the mycelium of Botrytis cinerea Pers. grown on barley grain medium (unhulled barley grain $10 \mathrm{ml}$; tap water $10 \mathrm{ml}$, autoclaved at $121^{\circ} \mathrm{C}$ for $20 \mathrm{~min}$ ) for one month. The Baermann funnel method was used to extract the nematodes from the fungus colonies, then the number of nematodes in the suspension was adjusted to 10,000 nematodes / $\mathrm{ml}$. Inoculation into the trees was done on 10 June, 2004, at the Kamigamo
Experimental Station of the Field Science Education and Research Center, Kyoto University. Fifteen-year-old Japanese black pines, Pinus thunbergii Parl., (average diameter at breast height $5.3 \mathrm{~cm}$, standard deviation 3.5 $\mathrm{cm}$ ) were inoculated as follows. The nematode suspension of $0.5 \mathrm{ml}$ aliquot was injected into a hole drilled in the bark at about $2.5 \mathrm{~m}$ above ground line. Cotton balls were put in the hole and another $0.5 \mathrm{ml}$ aliquot of the nematode suspension was injected, i.e. 10,000 PW Ns were injected into each tree. Next, the inoculation wound was sealed with Parafilm ${ }^{\circledR}$ (Pechiney Plastic Packaging, Inc. Chicago, IL, USA). Eighteen pine trees whose diameter at breast height ranged from 3.6 to $7.7 \mathrm{~cm}$ were inoculated with PW Ns, and the another three trees ranged from 5.3 to $5.7 \mathrm{~cm}$ were injected with distilled water (the control treatment). T he controls were needed to determine if the trees had been infected before inoculation.

Introduction of M onochamus alternatus larvae into pine stems:

The $M$. alternatus adults emerging from logs of dead Japanese black pine at the Tottori A rid Land Research Center of T ottori University were trapped. A pair of beetles were reared in a small cage and fed young pine twigs for food and oviposition. A fter 4 days, the eggs laid were collected from the twigs, dipped in $70 \%$ ethanol for $10 \mathrm{sec}$, then $0.05 \%$ benzethonium chloride for $5 \mathrm{~min}$, and then rinsed three times in sterile distilled water (Kosaka and Ogura, 1990; Kosaka and Enda, 1991). The eggs were then placed in microplate wells, each containing $500 \mu$ of $1 / 10$ PDA medium, and kept under aseptic conditions until they hatched.

On 6 July, 2004, when the inoculated pine trees ceased resin exudation, the stem of each tree was drilled at 8 points (each $25 \mathrm{~cm}$ apart) 75 to $250-\mathrm{cm}$ above ground line height and using a paintbrush one 1st stage larva of $\mathrm{M}$. alternatus 
was introduced into each hole. Wood sampling:

On 10 A ugust, 13 October and 16 December, 2004, 9 February, 10 A pril and 10 June, 2005, three dead trees were felled and a 10-cm-long wood block including one of the points where a larva had been introduced, and where a pupal chamber (PC) had been made, was arbitrarily collected from each tree. Each of the wood blocks was sliced into eight, 1-cm thick discs, and $2 \times 2 \mathrm{~cm}$ lattices were drawn on the cut surfaces. Then the discs were photocopied to record the position of PC and tunnels of $M$. alternatus. Then each of the discs was cut into $2 \times 2 \mathrm{~cm}$, squares along the line of the lattice, and each piece was split into two halves $(2 \times 1 \times 1 \mathrm{~cm})$. One half was used for isolating the nematodes and the other half for fungus isolation.

Each of the half pieces was sliced into small chips with pruning shears and placed in a Baermann funnel for 40 hours to extract the nematodes. A fter extraction, the chips were dried overnight at $105^{\circ} \mathrm{C}$ to determine their dry weight. The extracted nematodes were killed in water bath at $70-80^{\circ} \mathrm{C}$ for $2 \mathrm{~min}$ and then fixed in TAF (triethanolamine $2 \mathrm{ml}$; formalin $7 \mathrm{ml}$; distilled water $91 \mathrm{ml}$ ). Using a stereomicroscope and nematode counting slide the number of nematodes of each species was recorded. The results of fungal isolation will be reported in another paper.

M orphological identification of the nematodes:

The nematodes collected were processed by a quick method, consisting of fixation with warm lactophenol and preservation in glycerine (Siddiqi, 1964). The specimens were then mounted on slides and identified using a light microscope. Several morphological characters were used for identification according to Maggenti's system (Maggenti, 1991).

Data analysis:

Nematode numbers were calculated as num- bers of nematodes per gram of wood sample (dry weight basis). For the two most prevalent nematode species, Diplogasterida sp. 1 and B. xylophilus, a regression analysis was done after log-transformation of their numbers. A lso, the water content of the samples and log-transformed numbers of PWN was regressed. Samples that contained no PWN were not used for the analysis.

The ratio of the nematode populations in the wood samples with the PC and/or tunnel fractions, to that in the wood samples without PC or tunnel fractions was calculated for each disc, and thereby the degree of aggregation of each nematode species to the PC and tunnels of $M$. alternatus was evaluated.

\section{RESULTS}

Seasonal changes in nematode fauna:

Seasonal changes in nematode fauna and the population of each nematode species including the PWNs are shown in Fig. 1. During the experimental period, 15 nematode species were detected including the: (i) five mycophagous species; Bursaphelenchus xylophilus (PWN), Bursaphelenchus sp. 1, Bursaphelenchus sp. 2, Tylenchida sp. 1, Tylenchida sp. 2, (ii) nine saprophagous species; Diplogasterida sp. 1 , Diplogasterida sp. 2, Diplogasterida sp. 3, Diplogasterida sp. 4, Monhisterida sp. 1, Monhisterida sp. 2, Rhabditida sp. 1, Rhabditida sp. 2, Plectidae sp., and (iii) one predacious species; Mononchida sp. (Fig. 2). Over all seasons, PWN was the most abundant species, follow ed by Diplogasterida sp. 1. Interrelation between PWN and Diplogasterida sp. 1 in dead pine trees and its seasonal change:

Figure 1 shows that the population of Diplogasterida sp. 1 changed synchronously with that of PWN throughout the experimental period. However, the correlation between those two populations in the wood samples varied 


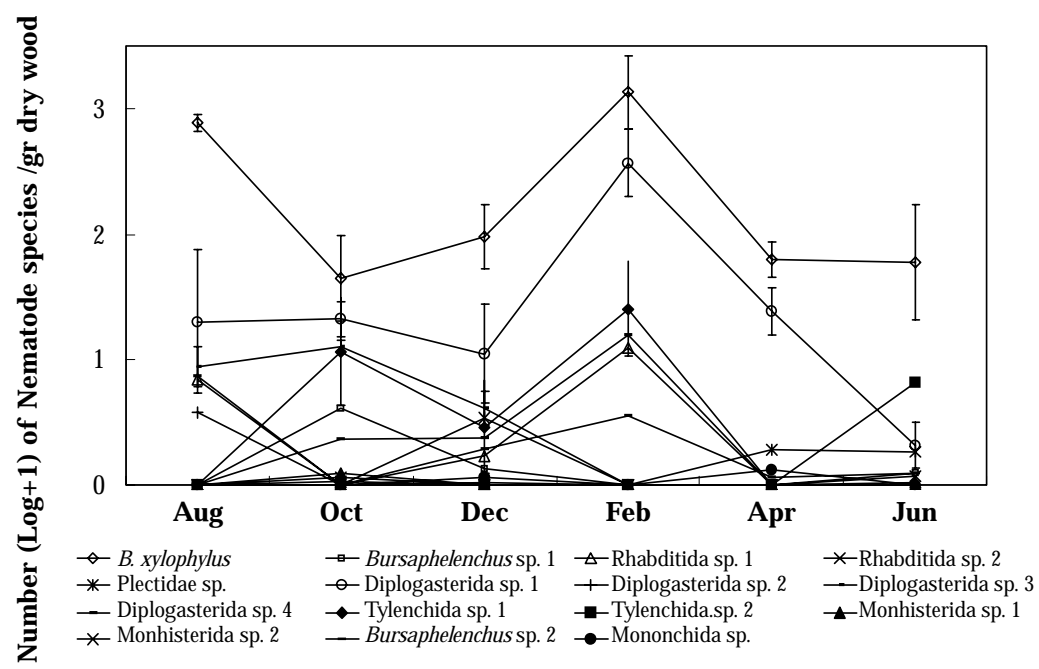

Fig. 1. Seasonal changes of nematode population of each species on dead pine trees. Each bar indicates standard error $(n=3)$.

from tree to tree (Fig. 3). Even in the same sampling season, except for February, no significant correlation was indicated between populations of the two nematode species. In some trees during December and June neither PWN nor Diplogasterida sp. 1 were found; consequently no correlation analyses could be made.

Effect of Monochamus alternatus pupal chambers on the number of nematodes:

Figure 4 shows the ratio between the numbers of nematodes in the wood samples with PC and/or tunnel fractions to those in the wood samples without them.

Beetle tunnels were first found on trees sampled in A ugust and PC first appeared in October. Both of the dominant species, PWN and Diplogasterida sp. 1, were more abundant in the wood samples with PC and/or tunnel fractions than in those lacking such structures. Thus, these two species preferably aggregated to PC and tunnels. The other nematode species did not show any preferable aggregation to PC or tunnels, and at some sample dates, they were not detected.

Relationship between the number of $B$. xylophilus and the water content of dead pine trees:

The relationship between water content of wood samples and the population of $B$. xylophilus varied from tree to tree (Fig. 5). In December positive correlation was observed between these two parameters, though no consistent correlation was observed in other sampling times.

\section{DISCUSSION}

When trees become diseased, the physical conditions within the trees, such as water content, temperature, change dramatically (Shigo, 1967). This invokes corresponding changes in microbial flora in the trees and thereby the nematode fauna must change promptly.

Previous studies on the seasonal change in nematode fauna in dead pine trees focused on the number of the PWN and 'free-living' nematodes, however, the latter nematodes were not identified to species, but instead just recorded as 'free-living nematodes' (Futai et al., 1986; Fukushige and Futai, 1987). A study of the nematode fauna associated with dead Pinus koraien- 

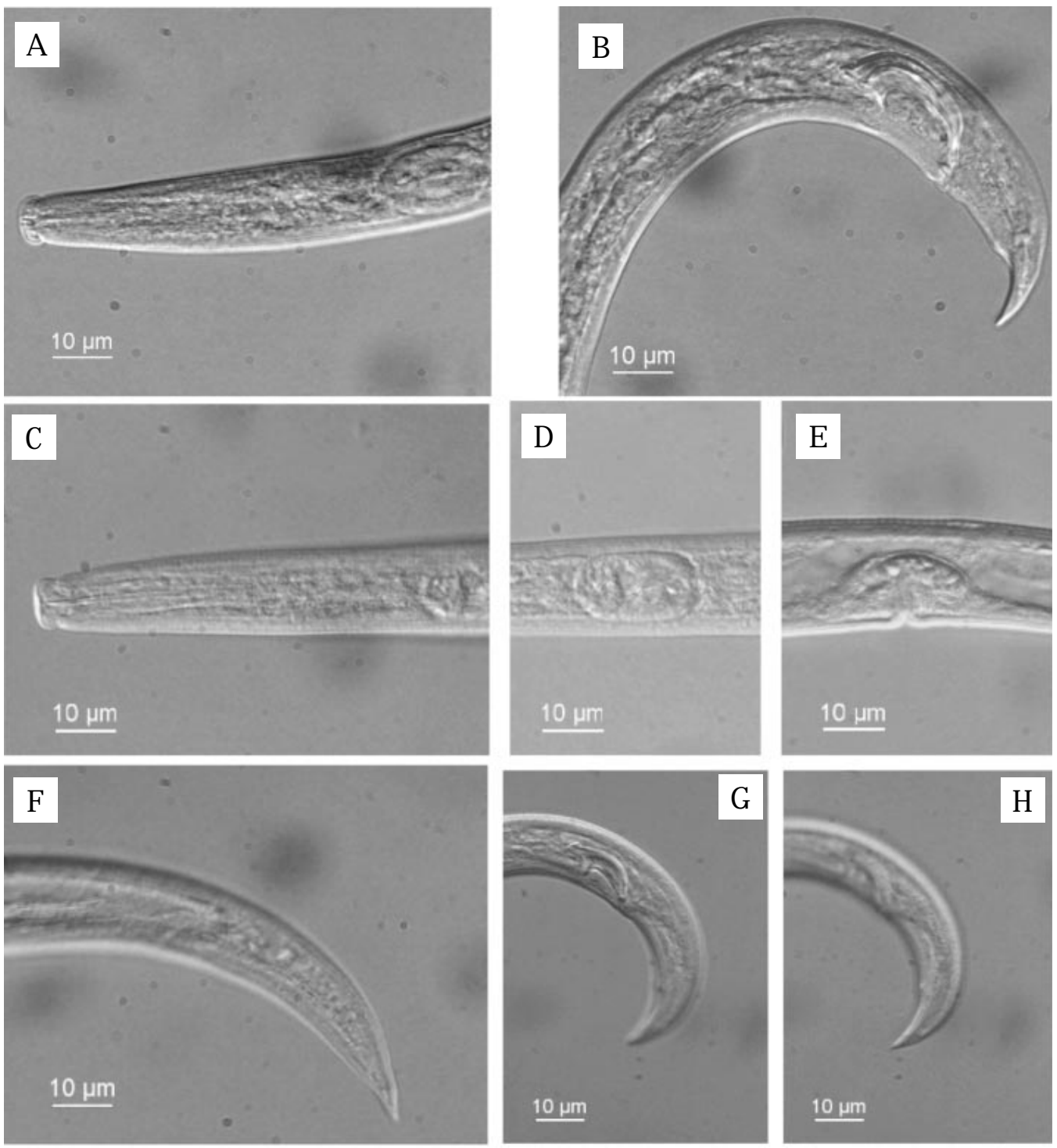

Fig. 2. A -B: Bursaphelenchus xylophilus. A : A nterior region. B: Male tail with bursa. C-H: Bursaphelenchus sp. 1. C: A nterior region. D: Median bulb. E: Vulval region. F: Female tail with inconspicuous rectum and anus. G: Spicule H: Male tail with bursa. I-J: Diplogasterida sp. 1. I: A nterior region. J: Male tail. K-L: Diplogaterida sp. 3. K: A nterior region. L: Female tail. M-N: Monhisterida sp. 1. M: A nterior region. N: Spicule. O-P: Mononchida sp. O: A nterior region. P: Female tail. Q-R: Rhabditida sp. 1. Q: A nterior end with median bulb. R: Median and basal bulb (with valve). S-T: Plectidae sp. S: A nterior end. T: Basal bulb. U-W: Tylenchida sp. 1. U: A nterior region. V: Female tail. W: Male tail. $X$-Z: T ylenchida sp. 2. X: A nterior region. Y: T ail region. Z: T ail tip. 

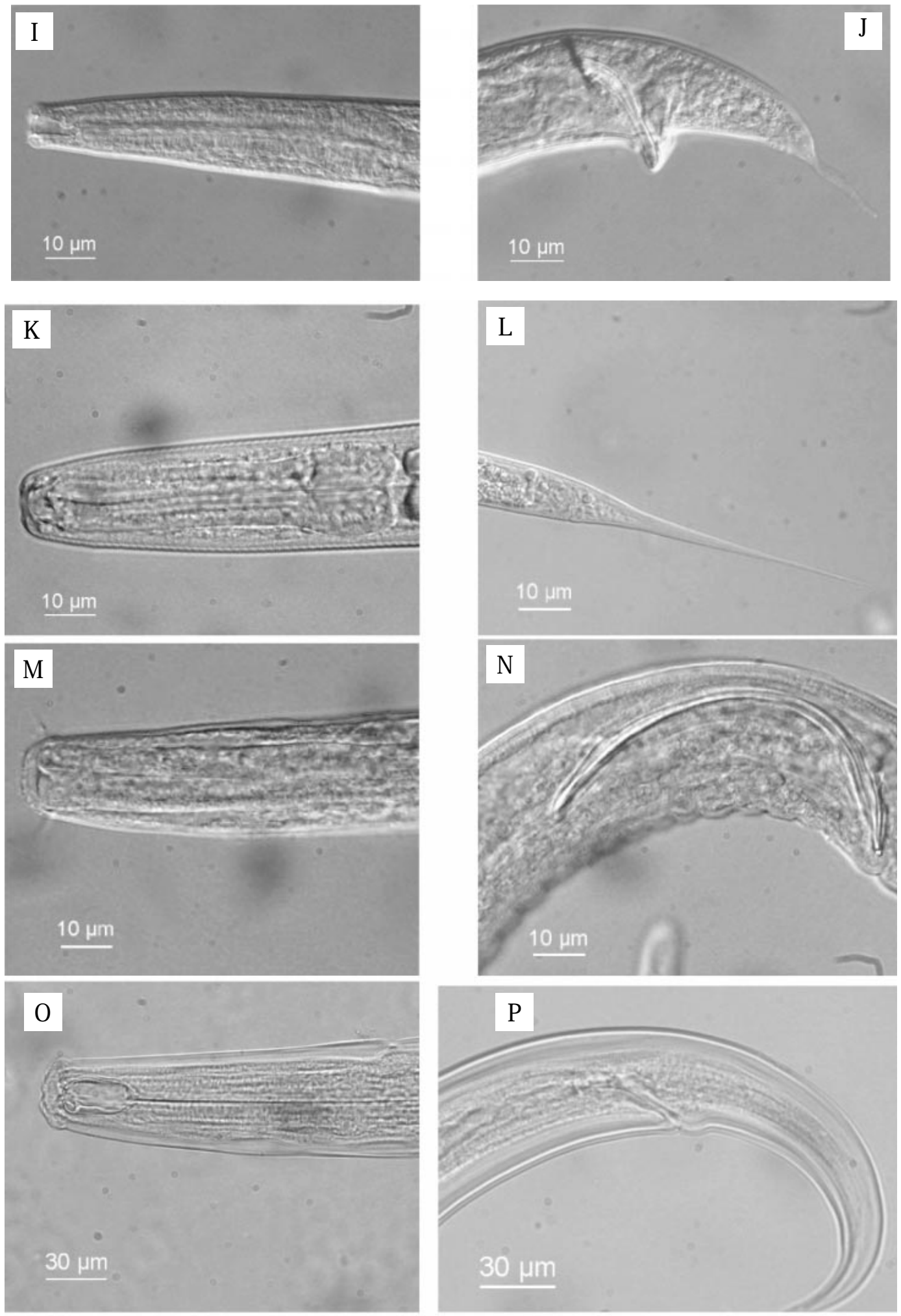

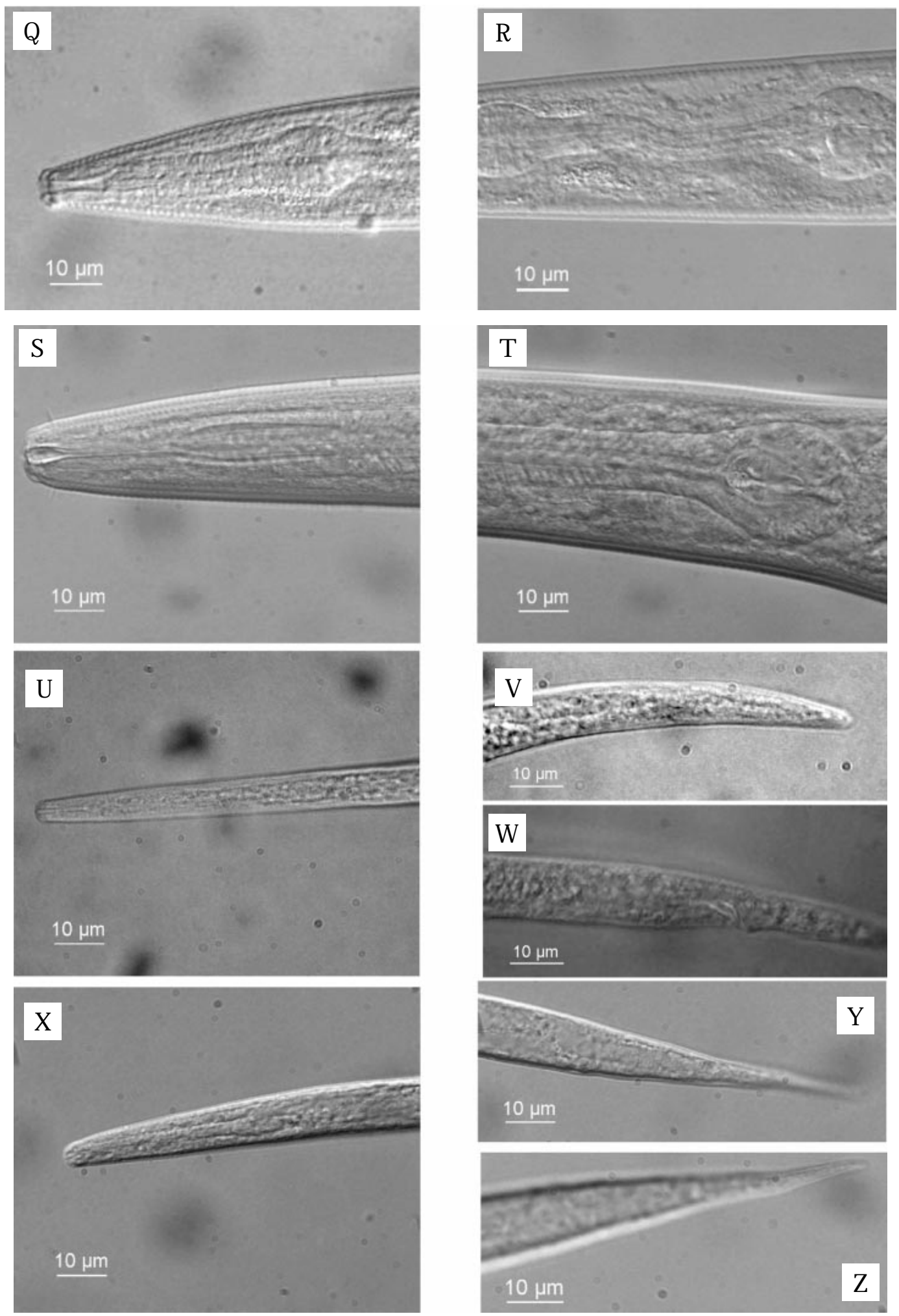

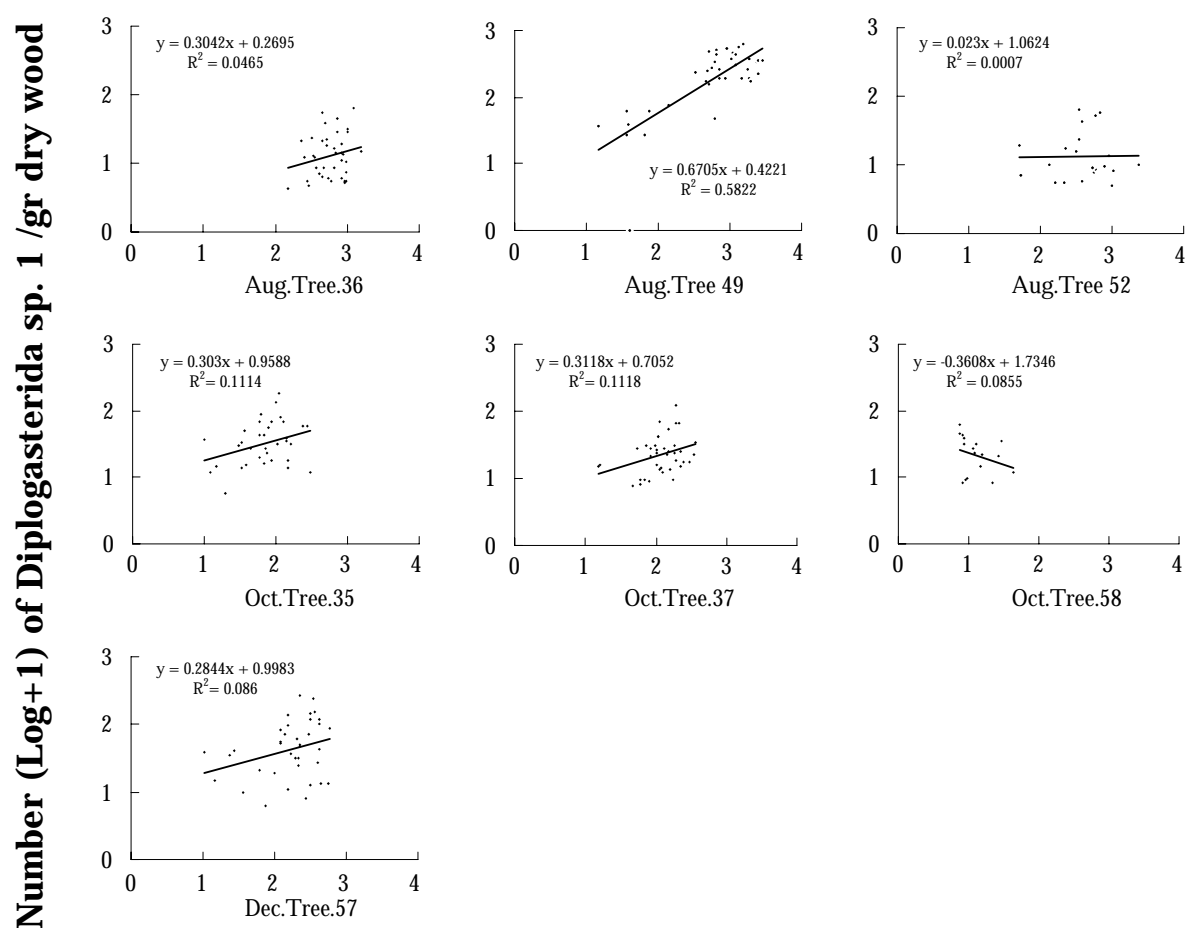

Number $(\log +1)$ of B. xylophilus/gr dry wood
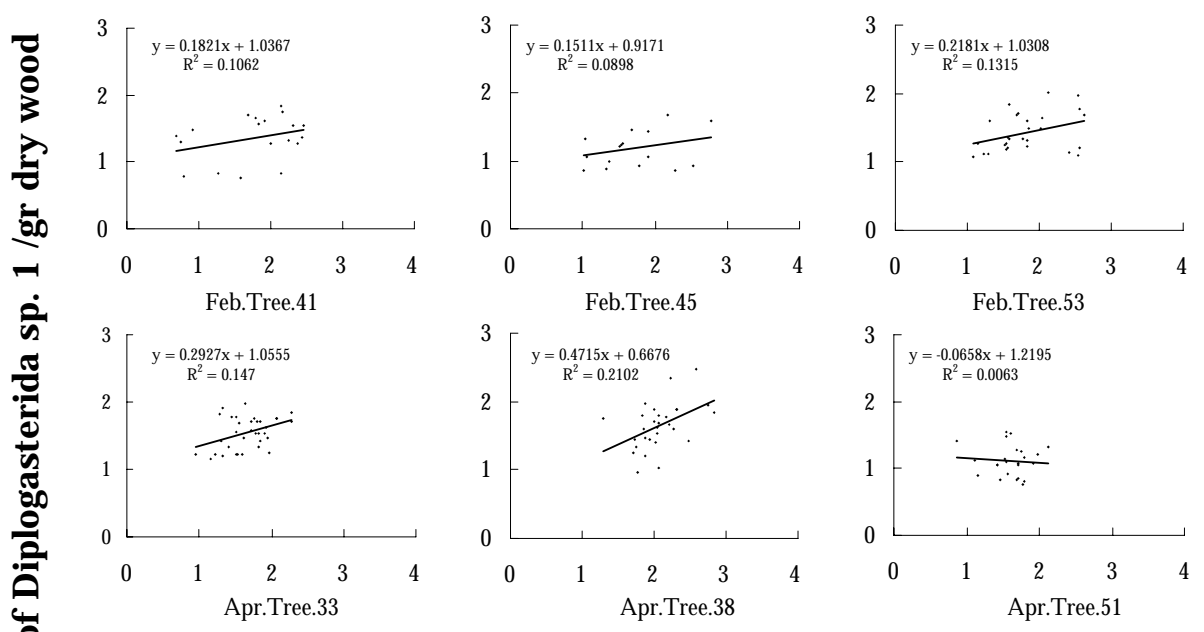

ำ

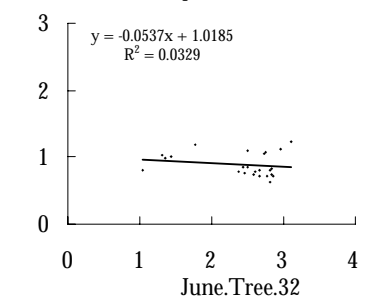

\section{Number (Log+1) of B. xylophilus/gr dry wood}

Fig. 3. Relationship between the number of Bursaphelenchus xylophilus and that of Diplogasterida sp. 1 on dead pine trees. 
B. xylophilus

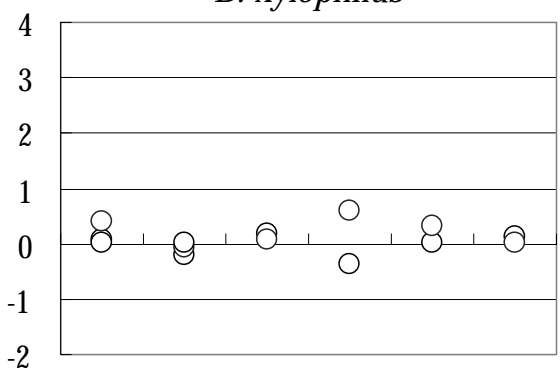

Diplogasterida sp. 3

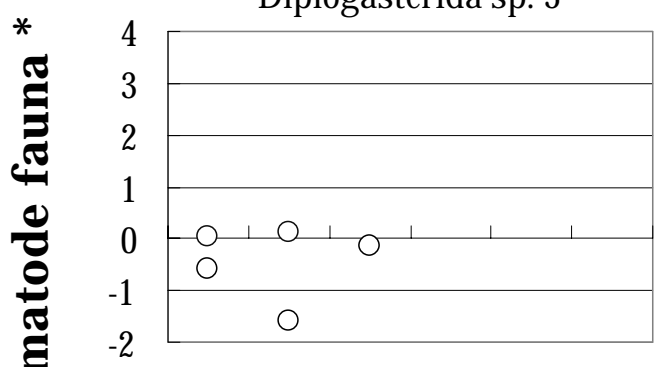

Plectida sp.

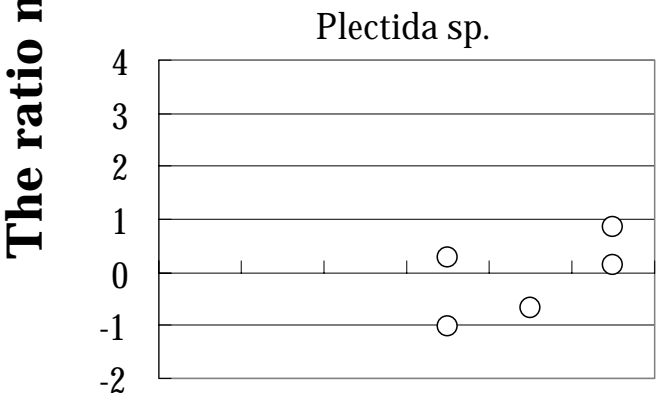

Tylenchida sp. 1

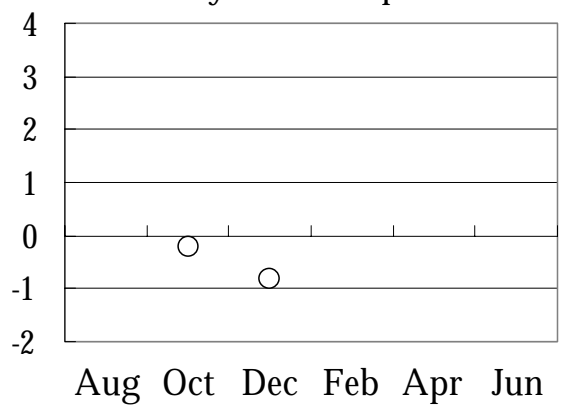

Diplogasterida sp. 1

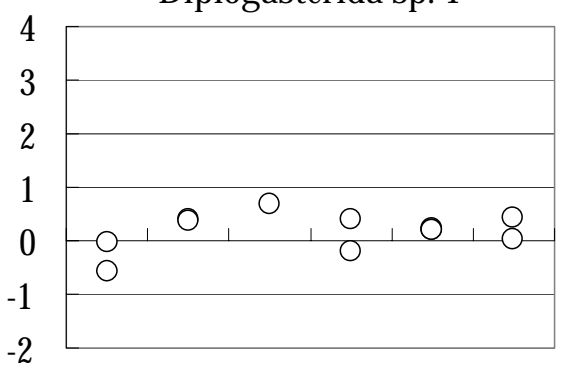

Diplogasterida sp. 4

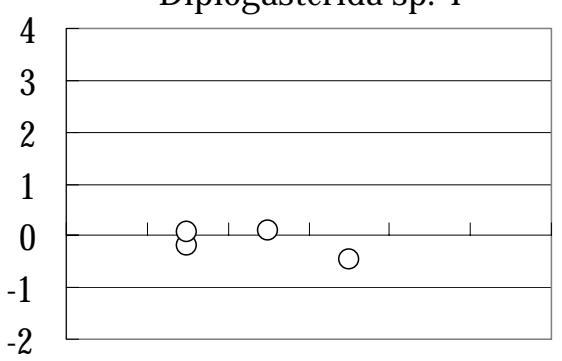

Rhabditida sp. 1

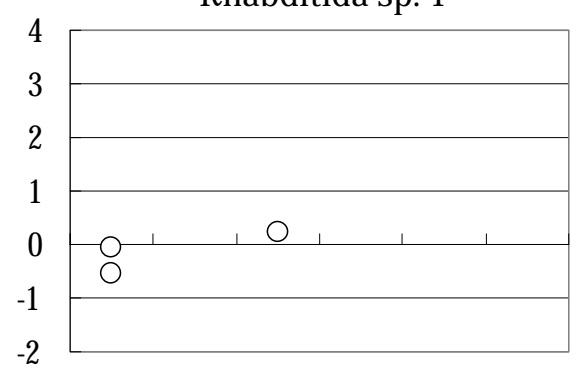

Tylenchida sp. 2

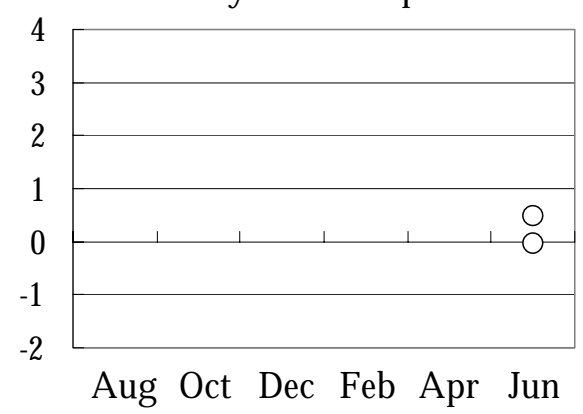

Fig. 4. E ffect of pupal chambers of M onochamus alternatus on the nematode population.

*T he ratio of nematode population in the wood samples including PC and/or tunnel fractions to that in the wood samples without them 

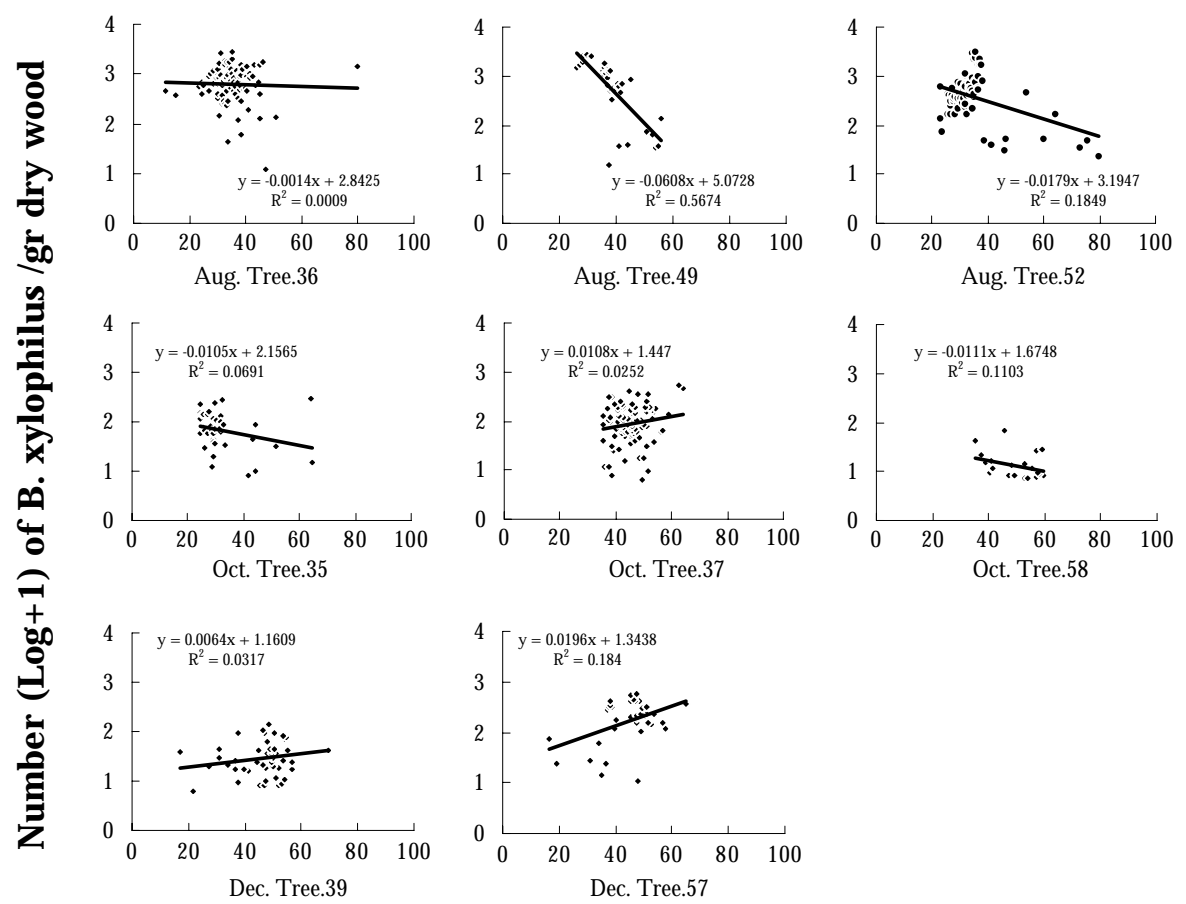

\section{W ater content (\%)}
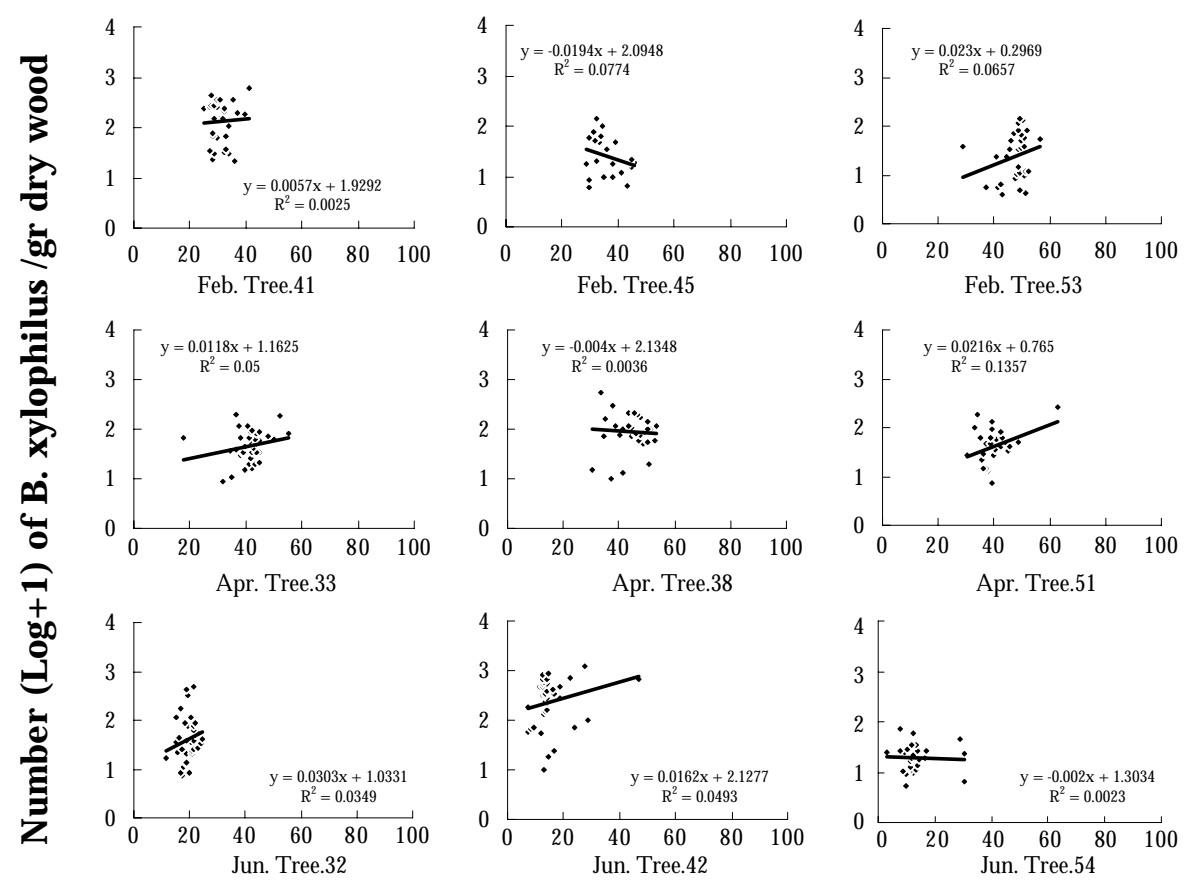

\section{W ater content (\%)}

Fig. 5. Relationship between the number of Bursaphelenchus xylophilus and that of water content on dead pine trees. 
sis trees in Primorye, Russia, showed a wide variation in nematode species (Kruglik, 2003), mostly they were mycophagous or saprophagous nematodes. As well, nematodes belonging to the order A phelenchida were quite abundant in dead wood of the Russian trees.

In the present study, 15 species of nematodes were identified, including mycophagous species, such as two species each of Tylenchida and three species of Bursaphelenchus, and nine saprophagous species (Figs. 1 and 2). T wo species of Tylenchida were considered to be mycophagous because they reproduced on fungus mycelium which grew from the wood on PDA. Interestingly females of one species of the genus Bursaphelenchus had an indistinct anus or lacked one, which is characteristic of the nematodes in the genera Ektaphelenchus and Cryptaphelenchus. Braasch (2004) described a Bursaphelenchus species with characteristics like those of Ektaphelenchidae species collected in China. The Bursaphelenchus species described by Braasch is very similar to ours in that it has an indistinct anus. Further studies are needed to determine if Bursaphelenchus sp. 1 is a new species and also to clarify its phylogenetic relationship with other nematodes.

The number of the PW Ns decreased until December but increased in February, then decreased again until June when the experiment terminated. Some trees contained large PW N populations in June. Fukushige and Futai (1987) reported a similar fluctuation in the number of PWN which decreased from October to December and increased from December to February. A gain, as we found here (Fig. 5), there was no correlation between nematode numbers and host water content. Kiyohara and Suzuki (1975) found that the percentage of dispersal third-stage juvenile (III) of the PW N in standing trees increased over time, reaching 60 to $100 \%$ by winter, but in the present study we did not distinguish JIII from other PW N developmental stages.

Futai et al. (1986) studied population changes of both PWN and other free-living nematodes in insecticide-treated and non-treated pine logs. Their studies showed that the population density of PWN was positively correlated with that of the free-living nematodes from November to the following January, while the number of the free-living nematodes decreased from October to November, then increased again in February. The present study examined the correlation between each of the free-living species and PWN. The population change of Diplogasterida sp. 1 was related to that of PW N at tree level over the experimental period (Fig. 1). At the microhabitat level $(2 \times 1 \times 1 \mathrm{~cm}$ of wood pieces) however, consistent correlation patterns were rare between PW N and any other nematode species. These results suggest that there might be a positive relationship between PWN and Diplogasterida sp. 1, but distribution of either nematodes among wood pieces were more or less at random. Consequently, it was not possible to detect any relationship between them at the microhabitat level. Kanzaki et al. (2002) isolated both Rhabdontolaimus psacotheae (Diplogasterida: Diplogasteridae) and Bursaphelenchus conicaudatus from adults of the yellow-spotted Iongicorn beetle, Psacothea hilaris (Coleoptera: Cerambycidae) emerged from fig trees, Ficus carica. Kanzaki and Futai (2002) also found these two nematodes to be sympatric in their vector's body and in their host fig trees. Differences in their food preference in host trees and in the part of the vector body must enable $R$. psacotheae and $\mathrm{B}$. conicaudatus to be sympatric. In the present study, a large population of both of Diplogasterida sp. 1 and PW N congregated around both PC and tunnels, perhaps difference in feeding habit of these two nematodes makes them to be sympatric. 
In natural stands, PWN is carried from wiltkilled to healthy pines by $M$. alternatus ( $M$ amiya and Enda, 1972; Morimoto and Iwasaki, 1972). The more PWNs that aggregate around the PC of $M$. alternatus in wilt-killed pines seems to increase the numbers of PWNs carried by the beetles which emerged from the PC (M aehara et al., 2005). Kobayashi et al. (1974, 1975), Fukushige (1991) and Maehara and Futai (2000) reported that the blue-stain fungi which prevailed around PC would serve as food for PWN. A s such intense blue-stain on the walls of $M$. alternatus $P C$ increased the number of PWN aggregating around these PC (Maehara et al., 2005). In our study, several mycophagous nematodes such as species of Tylenchida, two species of Bursaphelenchus and PW N were detected, but only PWN preferred to aggregate around PC. In most cases, however, not only mycophagous PWN but also saprophagous Diplogasterida sp. 1 was more abundant around PC and tunnels than elsewhere in the wood. PC and tunnels might provide suitable humidity and sufficient nutrients for growth and reproduction of fungi and other microbes, including food for nematodes. In our field studies we found that many factors could affect the microclimate of PC and tunnels. Environmental conditions and other fungal species besides blue-stain fungi also seem to play an important role in providing suitable conditions for propagation of the PW N. M onochamus beetles should introduce many organisms, including various fungi into pine trees. This study focused on the nematode fauna, but more studies are needed to clarify the exact relationship between PW N and the fungi that co-inhabit in dead pine tree.

\section{ACKNOWLEDGEMENT}

We sincerely thank Dr. J.R. Sutherland, Consultant, Canada, for critical reviewing this manuscript. We thank Yuko Takeuchi for help- ful translation comments.

\section{LITERAT URE CITED}

Braasch, H. (2004) A new Bursaphelenchus species (Nematoda: Parasitaphelenchidae) sharing characters with Ektaphelenchidae from the People's Republic of China. Zootaxa 624, 1-10.

Fukushige, H. (1991) Propagation of Bursaphelenchus xylophilus (Nematoda: A phelenchoididae) on fungi growing in pine shoot segments. A pplied Entomology and Zoology 26, 371-376.

Fukushige, H. and Futai, K. (1987) Seasonal changes in Bursaphelenchus xylophilus population and occurrence of fungi in Pinus thunbergii trees inoculated with the nematode. Japanese Journal of Nematology 17, 816.

Futai, K., Nakai, I., Fukiharu, T. and A kai, T. (1986) Ecological studies on the infection sources of pine wilt (I). Population dynamics of pine wood nematodes in the withered stems of Japanese red pine. Bulletin of the Kyoto University Forests 57, 1-13 (in Japanese with English summary).

de Guiran, G. and Bruguir, N. (1989) Hybridization and Phylogeny of the pine wood nematode (Bursaphelenchus spp.). Nematologica 35, 321-330.

Kanzaki, N., Minagawa, N. and Futai, K. (2002) Description of Rhabdontolaimus psacotheae n. sp. (Diplogasterida: Diplogasteridae), isolated from the yellow-spotted longicorn beetle Psachothea hilaris (Coleoptera: Cerambycidae) and fig trees, Ficus carica. Japanese Journal of Nematology 32, 7-12.

Kanzaki, N. and Futai, K. (2002) Life history of Rhabdontolaimus psacotheae $n . s p$. (Diplogasterida: Diplogasteridae), and its habitat segregation from Bursaphelenchus conicaudatus

(A phelenchida: 
A phelenchoididae). Japanese Journal of Nematology 32, 60-67.

Kiyohara, T . and Suzuki, K. (1975) Population

changes of Bursaphelenchus lignicolus in Pinus thunbergii after inoculation. Transactions of the 86th A nnual Meeting of Japanese Forestry Society, 296-298 (in Japanese).

Kobayashi, T., Sasaki, K . and M amiya, Y . (1974) Fungi associated with Bursaphelenchus lignicholus, the pine wood nematode (I). Journal of the Japanese Forestry Society 56, 136-145 (in Japanese with English summary).

Kobayashi, T., Sasaki, K . and M amiya, Y . (1975) Fungi associated with Bursaphelenchus lignicolus, the pine wood nematode (II). Journal of the Japanese Forestry Society 57, 184-193 (in Japanese with English summary).

Kosaka, H. and Ogura, N. (1990) Rearing of the Japanese pine sawyer, M onochamus alternatus (Coleoptera: Cerambycidae), on artificial diets. A pplied Entomology and Zoology 25, 532-535.

Kosaka, H. and Enda, N. (1991) Simple rearing method of larvae of the Japanese pine sawyer, Monochamus alternatus (Coleoptera: Cerambycidae) on artificial diets. Forest Pests 40, 183-187 (In Japanese).

Kruglik, I.A . (2003) Distribution of nematodes inside trunk and branches of the dead 200 years old pine Pinus koraiensis. Russian Journal of Nematology 11, 140-141.

Maehara, N. and Futai, K. (2000) Population changes of the pinewood nematode, Bursaphelenchus xylophilus (Nematoda: A phelenchoididae), on fungi growing in pine-branch segments. A pplied Entomology and Zoology 35, 413-417.

Maehara, N., Hata, K. and Futai, K. (2005) Effect of blue-stain fungi on the number of Bursaphelenchus (Nematoda: A phelenchoididae) carried by Monochamus alternatus (Coleoptera: Cerambycidae). Nematology 7, 161-167.

Maggenti, A .R. (1991) Nemata: higher classification. In: Manual of agricultural nematology, ( Nickle WR eds.), Marcel Dekker, New Y ork, 147-187.

Mamiya, Y . (1988) History of pine wilt disease in Japan. Japanese Journal of Nematology 20, 219-226.

Mamiya, Y . (2004) Pine wilt desease in Japan. In: The pine wood nematode, Bursaphelenchus xylophilus. Proceeding of an international workshop, University of É vora, Portugal, A ugust 20-22, 2001. Nematology Monographs and Perspectives, Vol. 1 (M ota, M. and Vieira, P. eds.), B rill A cademic Publishers, Leiden, T he Netherlands, 9-20.

Mamiya, Y . and Enda, N . (1972) T ransmission of Bursaphelenchus lignicolus (Nematoda: A phelenchoididae) by M onochamus alternatus (Coleoptera: Cerambicidae). Nematologica 18, 159-162.

Morimoto, K. and Iwasaki, A . (1972) Role of Monochamus alternatus (Coleoptera: Cerambycidae) as a vector of Bursaphelenchus lignicolus (Nematoda: A phelenchoididae). Journal of the Japanese Forestry Society 54, 177-183 (in Japanese with English summary).

M ota, M.M., Braasch, H., Bravo, M.A., Penas, A.C., Burgermeister, W., M etge, K. and Sousa, E. (1999) First report of Bursaphelenchus xylophilus in Portugal and in E urope. Nematology 1, 727-734.

Shigo, A.L. (1967) Successions of Organisms in discoloration and Decay of wood. In: International Review of Forestry Research. Vol. 2 (Romberger, J.A. and Mikola, P. eds.), A cademic Press, New York, London, 237299.

Siddiqi, M .R. (1964) Studies on Discolaimus spp. (Nematoda: Dorylaimidae) from India. 
Zeitschrift für zoologische Systematik und Evolutionsforschung 2, 174-184.

Y ang, B. (2004) T he history, dispersal and potential threat of pine wood nematode in China. In: The pine wood nematode, Bursaphelenchus xylophilus. Proceeding of an international workshop, University of
Évora, Portugal, A ugust 20-22, 2001. Nematology Monographs and Perspectives, Vol. 1 (M ota, M. and Vieira, P. eds.), Brill Academic Publishers, Leiden, The Netherlands, 21-24.

Received May 18, 2006. 